\title{
The Anterior Spreader Flap: A Minimally Invasive Alternative to the Auto Spreader Flap in the Treatment of Patients with Nasal Valve Dysfunction
}

\author{
Stephan Bessler1, Konrad Mende ${ }^{2}$, Leonid Goubergrits ${ }^{3}$, Jan Osman ${ }^{3}$, Benedikt Strub ${ }^{2 *}$ \\ ${ }^{1}$ Clinic for Head and Neck Surgery, Zurich, Switzerland \\ ${ }^{2}$ Clinic for Hand-, Plastic- and Reconstructive Surgery, Cantonal Hospital, Aarau, Switzerland \\ ${ }^{3}$ Biofluid Mechanics Lab, Institute of Laboratory Medicine, Charité, Berlin, Germany \\ Email: ${ }^{\text {benistrub@gmx.ch }}$
}

Received 4 May 2014; revised 3 June 2014; accepted 2 July 2014

Copyright (C) 2014 by authors and Scientific Research Publishing Inc.

This work is licensed under the Creative Commons Attribution International License (CC BY). http://creativecommons.org/licenses/by/4.0/

(c) (i) Open Access

\begin{abstract}
We present a new method of treatment for nasal valve dysfunction caused by insufficiency or stenosis in a patient who refused open septum revision despite a significant degree of septum deviation. The Anterior Spreader Flap (ASF) technique was suggested as an alternative to open nasal septum revision and was performed under local anesthesia. Computational fluid dynamics (CFD) tests were performed pre- and post-operatively and our patient was asked to complete a self-assessment using a Visual Analog Scale (VAS) for nasal breathing ( $0=$ free nasal breathing, $10=$ complete nasal blockage) before and 12 months after surgery. The ASF is a minimally invasive endonasal procedure in which the caudal edge of the upper lateral cartilage is dissected from the septum, and folded inwards and fixed. The ASF allows for less airflow resistance and more free space. CFD techniques revealed a reduction in local pressure based on extended space. In addition, VAS scores improved from 9 to 2 points (right side) and from 8 to 2 points (left side). On the basis of these findings, the ASF technique can be considered a safe, minimally invasive spreader flap technique. It can easily be combined with other nasal surgical techniques, as it is necessary in most cases. In selected cases, the ASF may be performed as a single procedure in patients with nasal valve dysfunction caused by septum deviation as an alternative to open septum revision.
\end{abstract}

\section{Keywords}

Spreader Flap, Anterior Spreader Flap, Nasal Valve, Nasal Valve Dysfunction

\footnotetext{
${ }^{*}$ Corresponding author.
}

How to cite this paper: Bessler, S., Mende, K., Goubergrits, L., Osman, J. and Strub, B. (2014) The Anterior Spreader Flap: A Minimally Invasive Alternative to the Auto Spreader Flap in the Treatment of Patients with Nasal Valve Dysfunction. International Journal of Otolaryngology and Head \& Neck Surgery, 3, 184-189. http://dx.doi.org/10.4236/ijohns.2014.34034 


\section{Introduction}

Obstruction of nasal breathing is commonly multifactorial and can be caused by impairment of airflow at distinct narrow anatomic sites. Psychological reasons may also play a role. Modern diagnostic techniques have revealed the importance of the inner and outer nasal valves for optimal nasal airflow. Approximately $80 \%$ of inspiratory airway resistance is generated in the anterior part of the nose [1]. Narrowing between the septum and the extreme caudal edge of the upper lateral cartilage (ULC) has been shown to play the most significant role [1]. Zuckerkandl named this narrow portion of the nasal cavity the "ostium internum" or "isthmus nasi". The term "nasal valve" was introduced by Mink [2]. During inspiration, negative pressure is generated at the site of the nasal valve which leads to medialization of the lateral nasal wall and an increase in nasal airway resistance [1] [3]. Any additional element that causes further narrowing of the airways at this site leads to a significant increase in airway resistance. A number of surgical techniques have been described to improve airflow in the nasal valve area [4] [5]. Based on the "auto spreader" technique described by Fomon [6] and Gruber [7], we developed a new, minimally invasive variant which we have named the “Anterior Spreader Flap” (ASF). In this article we describe the surgical technique of the ASF and illustrate the effects on nasal breathing by means of computational fluid dynamics (CFD).

\section{Case}

A 36-year-old male patient presented in October of 2012 for a second opinion regarding bilaterally impaired nasal breathing. Prior surgical history included two nasal operations (septoplasty and bilateral turbinoplasty) in 2010 at a different hospital, also because of impaired nasal breathing. Despite prior surgery, our patient reported no significant improvement in his symptoms.

\subsection{Preoperative Findings}

Clinical (especially palpation) and radiological (CT scan) examination revealed a strongly deviated septum with bilateral narrowing of the nasal valve (Figure 1).

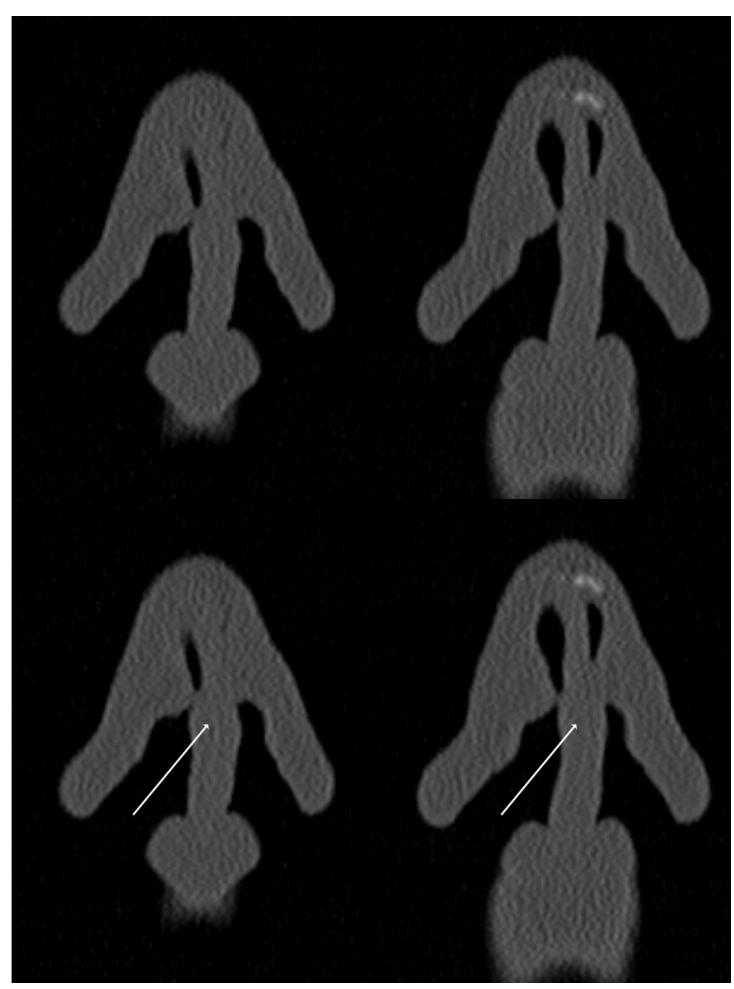

Figure 1. CT scan of the nasal valve area with ULC and septum (white arrow shows the deviated septum). 
Self-assessment of nasal obstruction by means of a nasal resistance score on a Visual Analog Scale (VAS) (10 $=$ impossible to breathe through the nose; $0=$ free nasal breathing) resulted in 9 out of 10 points on the right side and 8 out of 10 on the left. Because the patient refused to undergo major surgical intervention under general anesthesia, we proposed performing an ASF under local anesthesia. Our patient agreed to undergo the operation and gave written informed consent for the publication of our results.

\subsection{Surgical Technique}

A schematic illustration of the surgical technique is shown in Figure 2.

Figure 3(a) depicts the pre-operative endonasal status. Preparation of the ULC is performed following submucous infiltration with 2 - $3 \mathrm{ml}$ 1\% lidocaine with epinephrine $0.0001 \%$. An intercartilaginous incision is subsequently performed in conjunction with a bilateral anterior hemitransfixing incision. The skin is carefully lifted from the cartilaginous nasal dorsum and the mucosa is dissected from the caudal edge of the ULC. The ULC is sharply separated from the dorsal septum over a length of $7-10 \mathrm{~mm}$, folded inwards proximally between septum and the lateral ULC (Figure 3(b)) and fixed with a 5 - 0 mattress suture (Figure 3(c)). The final step is re-fixation of the mucosa with an absorbable suture (Figure 3(d)) and introduction of a nasal tamponade for 48 hours to secure the ASF.

\subsection{Postoperative Findings}

The nasal tamponade was removed after 48 hours and the sutures 10 days post-operatively in an out-patient setting. During the 12 month follow-up visit, our patient confirmed an improvement in the nasal resistance score on the right side from 9 to 2 and from 8 to 2 on the left. There were no complications.

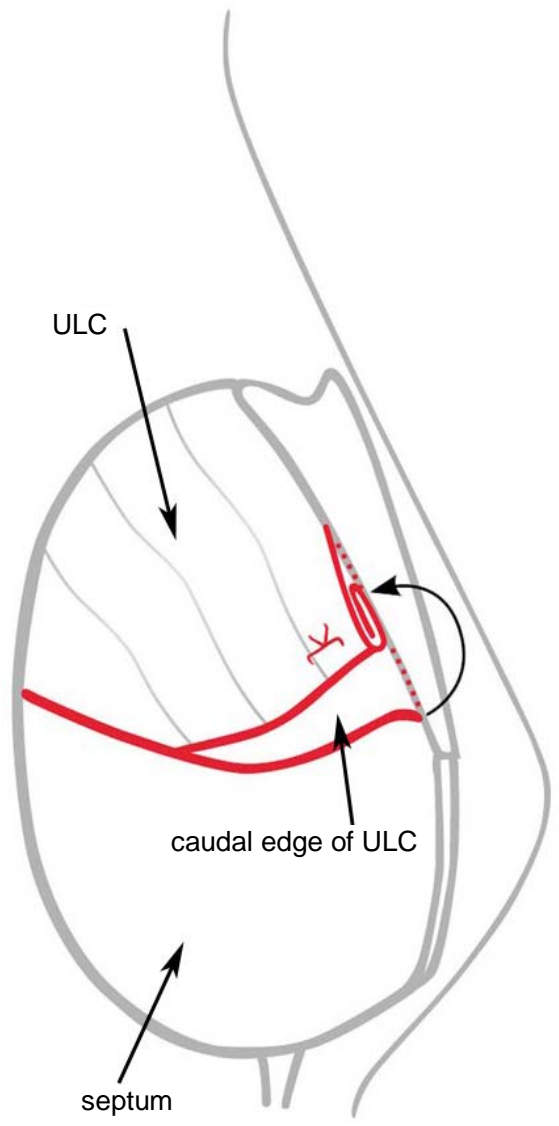

Figure 2. Schematic representation of the surgical technique infolding of the caudal part of the ULC. 


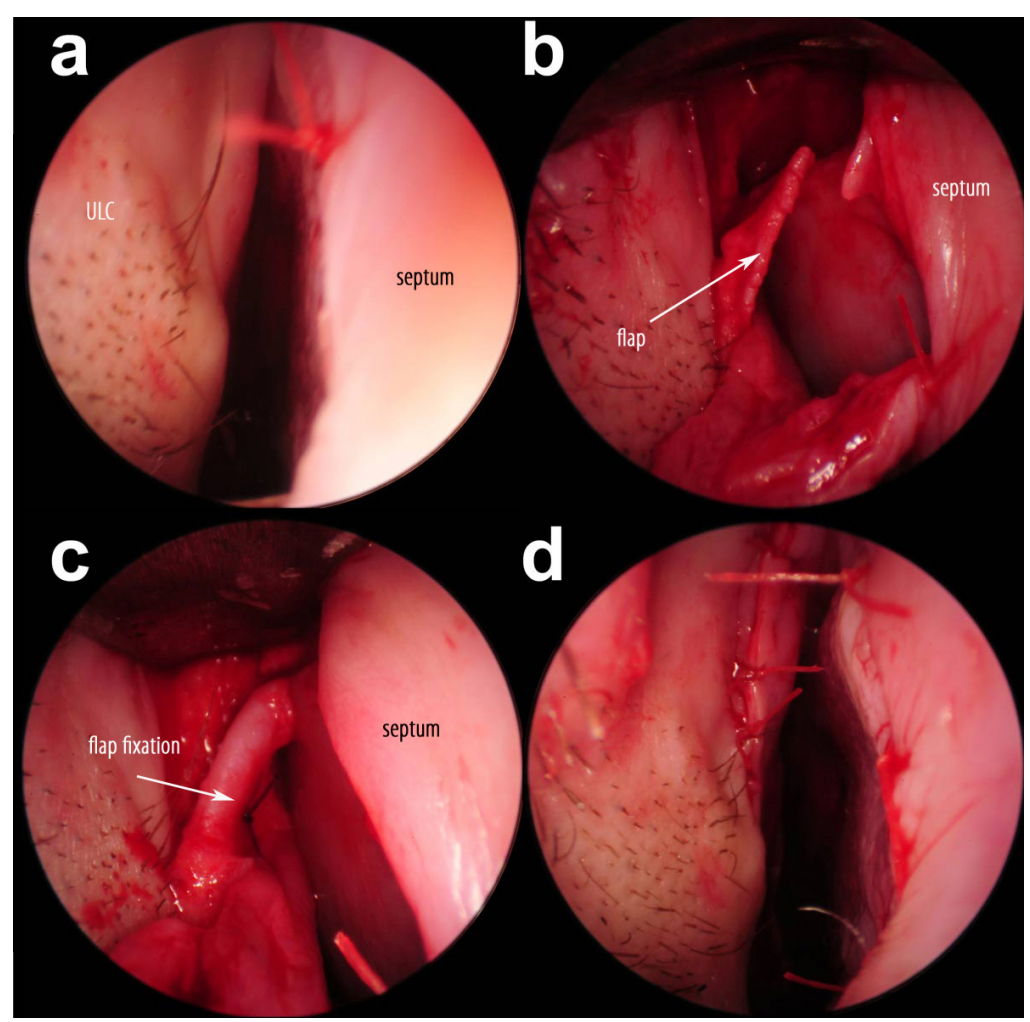

Figure 3. (a) Pre-operative endonasal situation before performing the ASF; (b) The ULC is dissected and detached from the septum; (c)The caudal part of the ULC is folded medially and fixed with a mattress suture; (d) Post-operative endonasal situation after ASF.

\subsection{CFD Findings}

CFD "steady flow" was simulated using the Fluent 6.3 Software (ANSYS Inc., Canonsburg, PA, USA). The technical details are consistent with the results of our previously published work [8]. The pre-operative CFD examination clearly demonstrates the pre-stenotic turbulence with an increased pressure gradient in the form of expansions. We call this area "free anterior spaces" (Figure 4).

The pre- and post-operative comparative CFD studies revealed signs of morphologic changes in the anterior part of the nose. These led to a pressure drop from pre-operative values of $3.77 \mathrm{~Pa}$ on the right and $3.76 \mathrm{~Pa}$ on the left to a post-operative value of 3.55 Pa on both sides (Figure 5). The preoperatively demonstrated "free anterior spaces” as a sign of an increased inspiratory pressure gradient were no longer detectable.

\section{Discussion}

We started using the ASF technique in 2010 for patients with nasal airflow obstruction. Because airflow obstruction is usually of multifactorial origin, the indication for a spreader flap as single treatment is rarely given. In accordance with other authors' previous experience [4] [9], we prefer to use the ASF in combination with other surgical treatments (septoplasty, turbinoplasty) to maximize functional output. Since 2010 we have treated more than twenty patients with the ASF and it was used successfully as a single procedure in four of these cases.

Due to the clinically relevant changes in the septal area, open extracorporeal septoplasty would have been indicated in the present case, but this was refused by the patient. We therefore performed the ASF as a single surgical procedure.

It is difficult to demonstrate the efficacy of spreader grafts and flaps alone because they are frequently performed in combination with other procedures. Moreover, the objective measurement of the precise extent of physical restrictions is limited in current clinical practice [4] [9]. In our experience, there is an inadequate correlation between rhinomanometry results and the patient's subjective symptoms. 


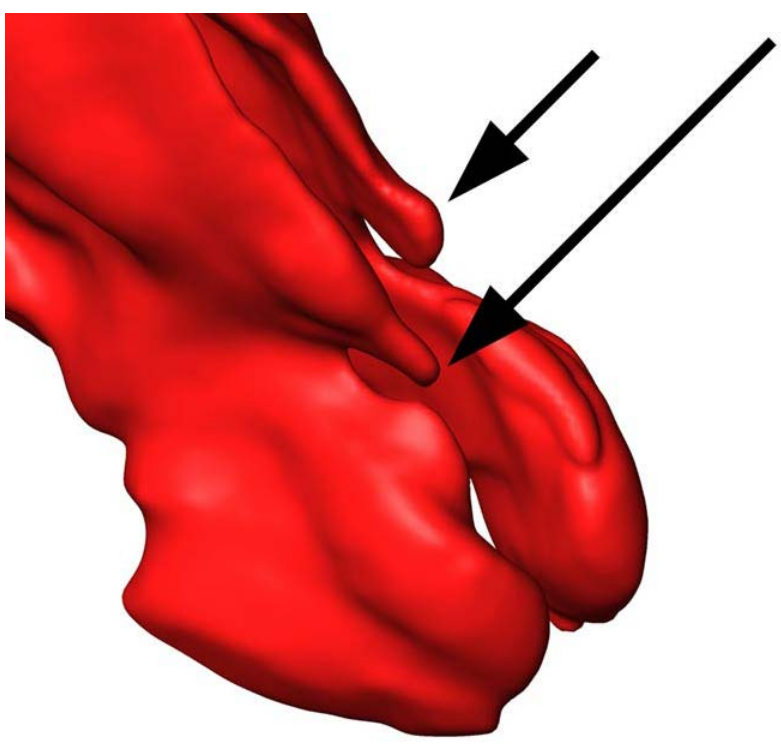

Figure 4. The pre-operative three-dimensional reconstruction shows the connection between the ULC and the septum (narrow passage) with the resulting "free anterior spaces" (short arrow left side, long arrow right side).

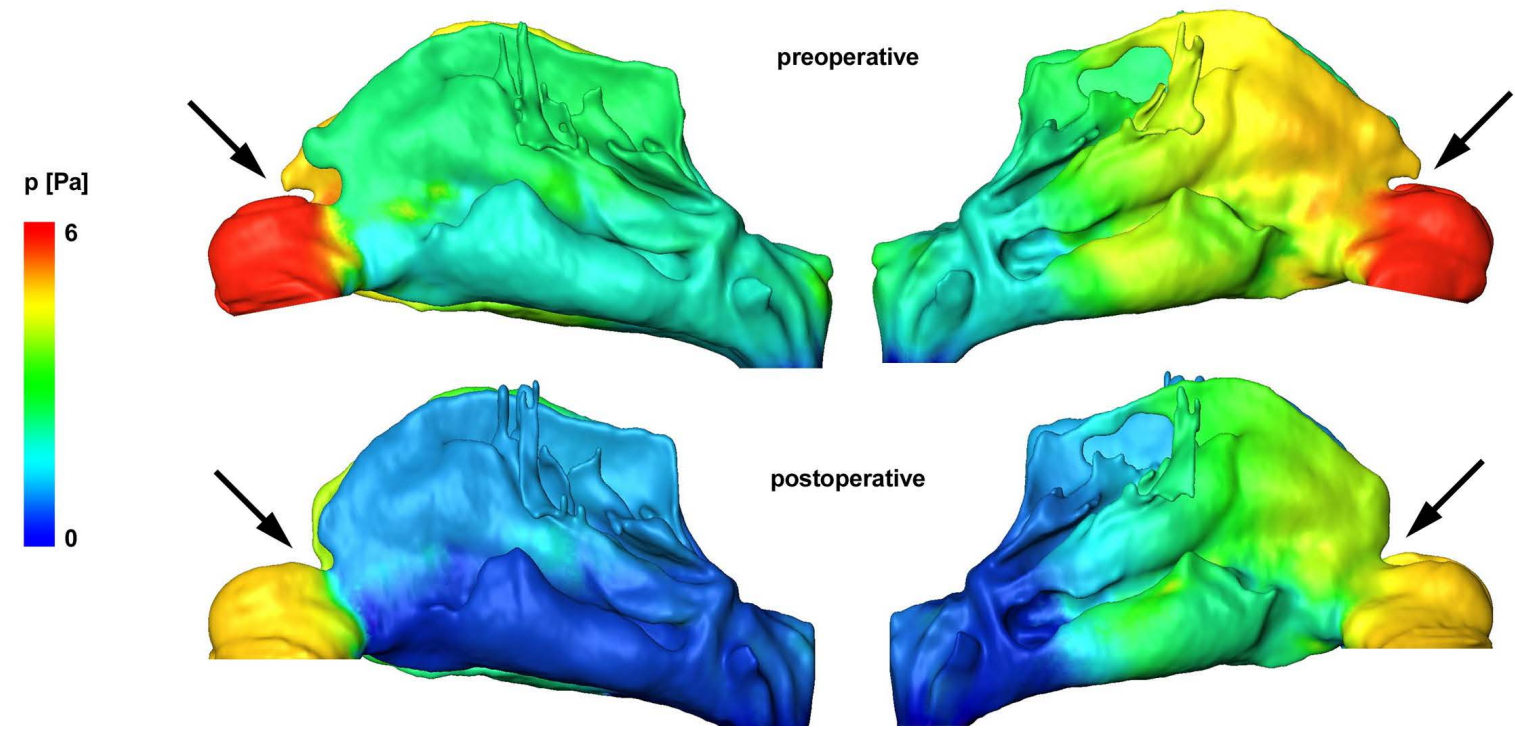

Figure 5. Pressure gradient in the nasal cavity during inspiration and morphological changes in the nasal valve after ASF (view of the lateral nasal wall). The arrows show the free anterior spaces of the nasal flow eliminated by the ASF.

We agree with André et al. [4] that pre- and post-operative nasal breathing scores reliably reflect the patient's symptoms and is an easily usable method in daily clinical practice. At present, the only suitable alternative is specialized imaging which allows the pre- and post-operative structural and physical status to be measured objectively.

CFD examinations, which are based on CT scans, allow for imaging and measurement of nasal flow conditions and the related pressure gradients in specific areas of the nose [8]. Nevertheless, a direct correlation with the patient's symptoms still has to be demonstrated.

The CFD results illustrate the morphological changes in the nasal cavity and decreased pressure gradients at the nasal valve, which indicate reduced nasal airway resistance. This was confirmed by our patient's subjective bilateral improvements in nasal breathing. Without any surgical procedure involving the nasal septum, post- 
operative self-assessment test results improved from 9 to 2 points on the right and from 8 to 2 points on the left.

The ASF is a non-resecting, minimally invasive variant of auto spreader grafts and can be performed under local anesthesia. The main advantage of our novel technique is that the nasal dorsum can be preserved over its full length.

For the preparation of the ULC, we recommend hydrodissection by submucous infiltration at the beginning of the procedure. To maintain stability of the nose, the scroll area must be preserved and not be detached from the lateral crus. The mucosa of the medial side of the ULC and the corresponding area of the septum are detached from the cartilage until the connection between the septum and the ULC can be sufficiently visualized. Preparation of the mucosa in this narrow area is very demanding and should be performed only by experienced nasal surgeons.

The caudal edge of the ULC is folded inwards in a proximal direction to the dorsal edge of the nasal septum, which leads to an increased cross section in the area of the limen nasi and to stabilization of the ULC. Re-fixation of the ULC to the septum is not required.

\section{Conclusion}

The ASF is an effective, minimally invasive option for supporting the nasal valve and extending the cross section of the nose. The main advantage of the ASF technique is that the nasal dorsum can be preserved over its full length. The ASF can easily be combined with other nasal surgical techniques (e.g. septum surgery), which is frequently required to efficiently treat the impairment of nasal breathing. In selected cases, if there are no additional cause for nasal obstruction, or if septum revision is not possible for any reason, the ASF may be performed as a single procedure.

\section{Conflicts of Interests}

There are no conflicts of interest.

\section{References}

[1] Wexler, D.B. and Davidson, T.M. (2004) The Nasal Valve: A Review of the Anatomy, Imaging, and Physiology. American Journal of Rhinology, 18, 143-150.

[2] Mink, P.J. (1920) Physiologie der Oberen Atemwege: Die Nasenhöhle. F.C.W. Vogel, Leipzig.

[3] Masing, H. (1967) Experimentelle Untersuchungen über die Strömung im Nasenmodell. Arch Klin Exper Ohren-, Nasen-, und Kehlkopfheilk, 189, 59-70.

[4] André, R.F. and Vuyk, H.D. (2008) Nasal Valve Surgery; Our Experience with the Valve Suspension Technique. Rhinology, 46, 66-69.

[5] Fischer, H. and Gubisch, W. (2006) Nasal Valves-Importance and Surgical Procedures. Facial Plastic Surgery, 22, 266-280. http://dx.doi.org/10.1055/s-2006-954845

[6] Fomon, S.G.J. and Caron, A.L. (1950) Collapsed Ala. Acta Otolaryngologica, 51, 465-484. http://dx.doi.org/10.1001/archotol.1950.00700020488001

[7] Gruber, R.P., Park, E., Newan, J., Berkowitz, L. and Oneal, R. (2007) The Spreader Flap in Primary Rhinoplasty. Plastic and Reconstructive Surgery, 119, 1903-1910. http://dx.doi.org/10.1097/01.prs.0000259198.42852.d4

[8] Hildebrandt, T., Goubergrits, L., Heppt, W.J., Bessler, S. and Zachow, S. (2013) Evaluation of the Intranasal Flow Field through Computational Fluid Dynamics. Facial Plastic Surgery, 29, 93-98. http://dx.doi.org/10.1055/s-0033-1341591

[9] De Pochat, V.D., Alonso, N., Mendes, R., Cunha, M.S. and Menezes, J. (2012) Nasal Patency after Open Rhinoplasty with Spreader Grafts. Plastic and Reconstructive Surgery, 65, 732-738. http://dx.doi.org/10.1016/j.bjps.2011.11.059 
Scientific Research Publishing (SCIRP) is one of the largest Open Access journal publishers. It is currently publishing more than 200 open access, online, peer-reviewed journals covering a wide range of academic disciplines. SCIRP serves the worldwide academic communities and contributes to the progress and application of science with its publication.

Other selected journals from SCIRP are listed as below. Submit your manuscript to us via either submit@scirp.org or Online Submission Portal.
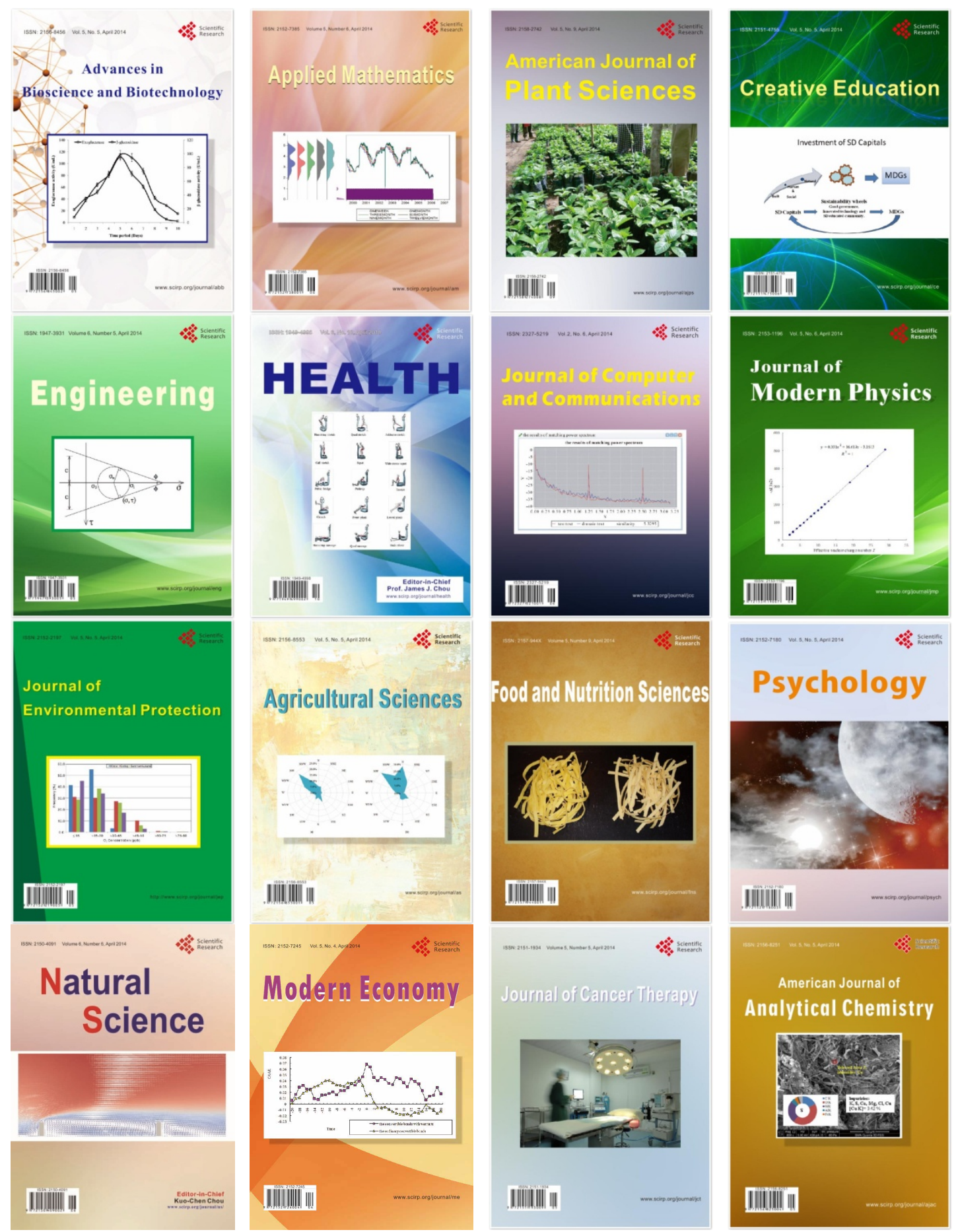